\title{
Wax Precipitation at Different Locations of Nigerian Crude Oil Production Line
}

\author{
Godwin A. Udourioh ${ }^{1 *}$, Ozioma Achugasim², Samuel E. Ofodile ${ }^{3}$, and I. P. Okoye ${ }^{4}$ \\ Department of Pure and Applied Chemistry, College of Natural and Applied Sciences, Veritas University, \\ Abuja (The Catholic University of Nigeria) ${ }^{1}$ \\ Department of Pure and Industrial Chemistry, Faculty of Sciences, University of Port Harcourt, \\ P. M. B. 5323, Choba, Rivers State, Nigeria ${ }^{2,4}$ \\ World Bank African Centre of Excellence in Oilfield Chemicals, Institute of Petroleum Studies (IPS), \\ University of Port Harcourt, P.M.B. 5323, Port Harcourt Nigeria ${ }^{3}$
}

\begin{abstract}
The Wax Appearance Temperature (WAT) and Wax Content (WC) of wellhead, flowline and separator crude oil samples were studied. The propensity for the crude oil to precipitate wax due to temperature changes was assessed by measuring the WAT while the quantity of wax precipitated was measured by the WC at the various locations of the production line. The results showed that the WAT for each of the test samples was highest at the wellhead, followed by the flowline and the separator. The WC was also highest at the wellhead, followed by the flowline and the separator. The trend of WAT and WC were therefore in the order: wellhead > flowline > separator. This result implies that the Wax Precipitation Envelope (WPE) for crude oils may not be the same along the production line from the wellhead to the separator.
\end{abstract}

Keywords: Wax Precipitation, Heavy organics, Wax precipitation envelope, Wax appearance temperature (WAT), Wax content.

\section{INTRODUCTION}

Temperature reduction is known to be a common factor responsible for wax precipitation. Wax precipitation is one of the most serious flow assurance problems in the petroleum industry [1,2,3]. Technical problems associated with wax precipitation and deposition include: permeability reduction and formation damage if occurred at the wellbore and its vicinity, reduction in the interior diameter and plugging of production strings and flow channels and changes in the reservoir fluid composition and rheology due to phase separation as wax precipitates. There could also be an additional strain on pumping equipment as well as limiting influence on the operation capacity of the entire production system[2,3,4].

Temperature decrease can be caused by oil and gas expansion at the formation face through casing perforations or other orifices or restrictions, by dissolved gas being liberated from solution, injection of water or other fluids at temperatures below the reservoir temperature, radiation of heat from the fluid to the surrounding formation as it flows up the wellbore and transfer of the fluid through low-temperature surface facilities $[4,5,6]$.

It is not all cases of wax precipitation anyway that result in deposition. Individual wax crystal may be dispersed and not deposited. However, wax tends to agglomerate, separate and deposit after precipitation if the wax crystals are large enough or if other nucleating materials such as asphaltenes, formation fines, clay, or corrosion products are present in the system $[3,4]$.

Petroleum waxes are generally categorized into two groups: macro-crystalline and microcrystalline waxes. The macrocrystalline waxes are commonly referred to as paraffin waxes. These are waxes formed mainly from normal paraffin. They consist of straight chain saturated hydrocarbons with carbon atoms ranging from $\mathrm{C}_{18}$ to $\mathrm{C}_{36}$ with $80-90 \%$ normal paraffin contents $[1,7,8]$. The microcrystalline or amorphous waxes are formed from iso-paraffin or naphthenes, that is, branched and cyclic aliphatic hydrocarbons. Their carbon atoms contents ranged from $\mathrm{C}_{30}-\mathrm{C}_{60}[1,8,9,10]$. Figure 1 shows some n-paraffin, iso-paraffin and naphthene structures. 


\section{International Advanced Research Journal in Science, Engineering and Technology}

Vol. 5, Issue 12, December 2018

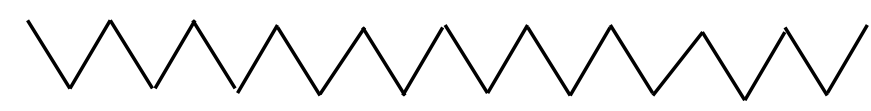

n-Paraffin (straight chains)

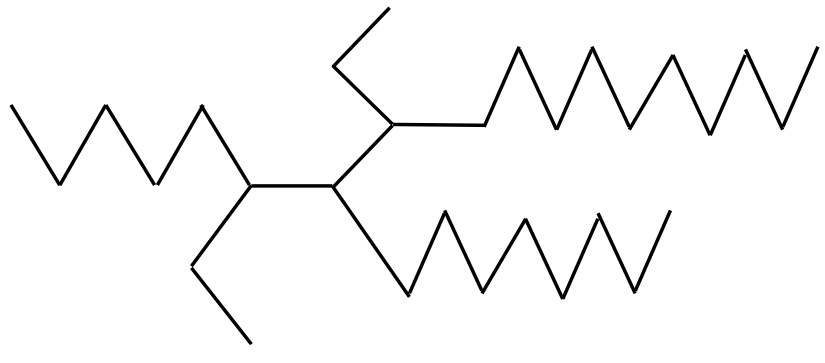

Iso-Paraffin (Branched chains)



Naphthene (Cyclo-paraffin)

Figure 1: Paraffin structures

Petroleum wax formation consists of two distinct stages: nucleation and crystal growth. Nucleation is the formation of wax clusters called nuclei as the temperature of a liquid solution is lowered to the wax appearance temperature (WAT). Wax appearance temperature (WAT) is the temperature at which wax starts to crystallize and separate out of solution [11]. It is a function of the properties of the crude oil, thermodynamic, physical and chemical properties. The chemical properties include the composition of the crude oil $[4,6]$. Wax molecules continue to attach and detach from the crystals until they reach a critical size and becomes stable. Crystal growth occurs once the nuclei are formed and the temperature remains below the wax appearance temperature (WAT). Further wax molecules are laid down in a platelike or lamellar structure $[4,12,13]$.

Wax precipitation is strongly temperature-dependent and weakly pressure-dependent [14]. The temperature-pressure relationship which defines the wax appearance as a function of these two variables is depicted on the pressure temperature wax precipitation envelope (WPE) by Leontaritis [4]. This envelope is drawn for each crude oil assumed to be representative of dead oil and is believed that the tendency and quantity of wax precipitation are the same at the various location of the production line irrespective of the changes in composition of the crude oil $[4,15]$.

This work therefore, studies the effect of temperature changes on wax precipitation at the various location of the petroleum production line in order to contribute to the determination of points of intervention in wax precipitation prevention measures.

\section{MATERIALS AND METHODS}

The crude oil samples were obtained from Niger Delta, Nigeria. Three different locations of the production lines (wellhead, flowline and separator) were sampled.

Measurement of the Wax Appearance Temperature (WAT) or Cloud Point: Automated cloud point tester designed for ASTM D2500 specification was used. 2 grams of the crude was weighed into a test tube, centrifuged, heated in a water bath to $60^{\circ} \mathrm{C}$ and inserted into the sample jar of the automated cloud point tester. The jar was cooled and monitored at $3^{\circ} \mathrm{C}$ intervals for cloudy appearance. The temperature at which the sample showed haziness of cloud was recorded as the WAT.

Wax Content (WC): The wax content was determined using a Modified Universal Oil Product method (UOP46) also known as Standard Acetone method [1, 16]. 2 grams of oil was added to 30mls of n-pentane and the solution clarified and resin adsorbed by adding Fuller's earth. It was filtered using vacuum pump system. As such, all polar materials including asphaltene were collected on the filter paper. The n-pentane solvent was vapourised from the clarified and deasphalted oil using rotary evaporator. The oil was re-dissolved in $75 \mathrm{ml}: 25 \mathrm{ml}$ (acetone: diethyl ether) mixture. The solution was cooled down to $-17^{\circ} \mathrm{C}$ and cold filtered using vacuum pump system with the wax collected on the paper fitted to the Buchner funnel. The wax precipitate was weighed and the weight percent calculated. 


\section{International Advanced Research Journal in Science, Engineering and Technology}

Vol. 5, Issue 12, December 2018

\section{RESULTS AND DISCUSSION}

The WAT of the three oil wells at the wellhead, separator and flowline are presented on Table 1. Table 2 and Figure 2 show the comparison between the wax appearance temperature (WAT) and the operational temperatures of the oil wells. The results on the wax content (WC) are presented in Table 3 and Figure 3.

Table 1: Wax appearance Temperature (WAT) in degree Celsius $\left({ }^{\circ} \mathrm{C}\right)$ or Cloud points of the oil samples

\begin{tabular}{llll}
\hline Oil Well & Wellhead WAT $\left({ }^{\circ} \mathbf{C}\right)$ & Separator WAT $\left({ }^{\circ} \mathbf{C}\right)$ & Flowline WAT $\left({ }^{\circ} \mathbf{C}\right)$ \\
\hline SAPW1 & $9 \pm 0.03$ & $6 \pm 0.11$ & $8 \pm 1.04$ \\
SAPW2 & $7 \pm 1.11$ & $4 \pm 0.21$ & $6 \pm 1.12$ \\
SAPW3 & $8 \pm 0.15$ & $5 \pm 0.32$ & $6 \pm 0.23$ \\
\hline
\end{tabular}

Table 2: The wax appearance temperature (WAT) and Operational Temperature $\left({ }^{\circ} \mathrm{C}\right)$ of the oil samples

\begin{tabular}{|l|l|l|l|l|l|l|}
\hline \multirow{2}{*}{$\begin{array}{l}\text { Oil } \\
\text { Well }\end{array}$} & \multicolumn{2}{|c|}{ Wellhead $($ WH $)$} & \multicolumn{2}{c|}{ Separator (SR) } & \multicolumn{2}{c|}{ Flowline (FL) } \\
\cline { 2 - 7 } & WAT $\left({ }^{\circ} \mathrm{C}\right)$ & $\begin{array}{l}\text { Operational } \\
\text { Temp }\left({ }^{\circ} \mathrm{C}\right)\end{array}$ & WAT $\left({ }^{\circ} \mathrm{C}\right)$ & $\begin{array}{l}\text { Operational } \\
\text { Temp }\left({ }^{\circ} \mathrm{C}\right)\end{array}$ & $\begin{array}{l}\text { WAT } \\
\left({ }^{\circ} \mathrm{C}\right)\end{array}$ & $\begin{array}{l}\text { Operational } \\
\mathrm{Temp}\left({ }^{\circ} \mathrm{C}\right)\end{array}$ \\
\hline SAPW1 & $9 \pm 0.03$ & 50 & $6 \pm 0.11$ & 39 & $8 \pm 1.04$ & 46 \\
\hline SAPW2 & $7 \pm 1.11$ & 45 & $4 \pm 0.21$ & 35 & $6 \pm 1.12$ & 42 \\
\hline SAPW3 & $8 \pm 0.15$ & 53 & $5 \pm 0.32$ & 41 & $6 \pm 0.23$ & 51 \\
\hline
\end{tabular}

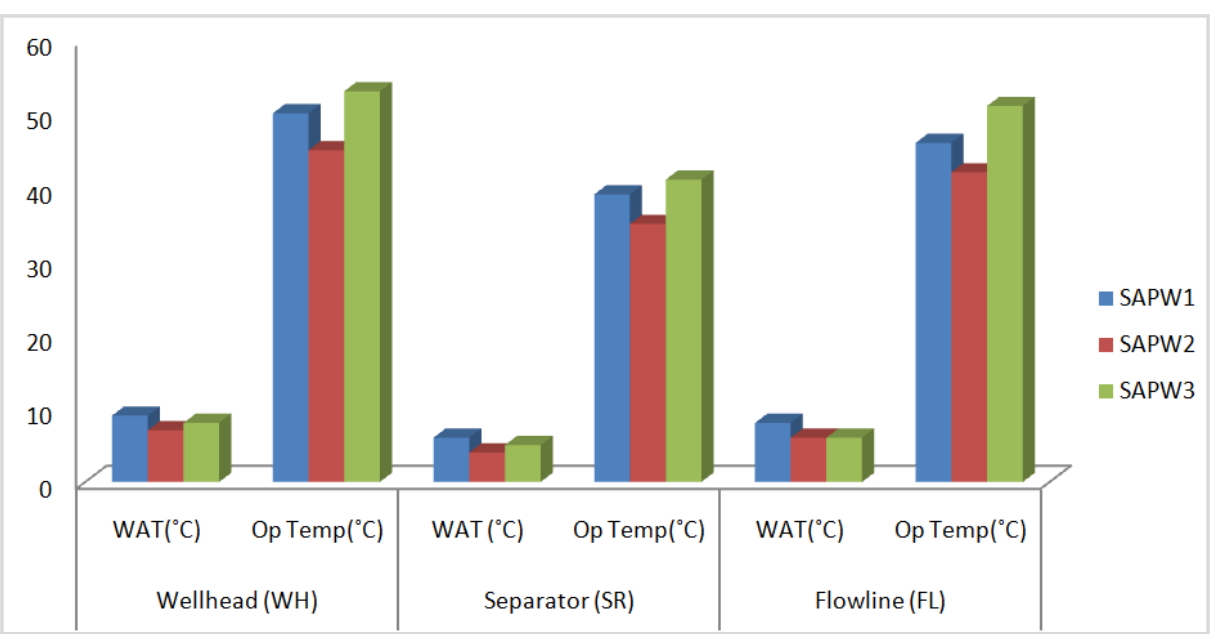

Figure 2: The Wax appearance temperature (WAT) and Operational Temperature $\left({ }^{\circ} \mathrm{C}\right)$ of the oil samples

Table 3: Weight Percentage (Wt. \%) of Wax Content with 95\% Confidence Limit and 2 Degree of Freedom

\begin{tabular}{llll}
\hline Oil Well & Wellhead (wt. \%) & Separator (wt. \%) & Flowline (wt. \%) \\
\hline SAPW1 & $13.15 \pm 0.12$ & $12.70 \pm 0.43$ & $13.03 \pm 0.03$ \\
SAPW2 & $10.60 \pm 0.05$ & $8.95 \pm 0.37$ & $10.06 \pm 0.03$ \\
SAPW3 & $10.07 \pm 0.31$ & $8.95 \pm 0.12$ & $9.03 \pm 0.15$ \\
\hline
\end{tabular}

From Table 1, the wax appearance temperatures of the wellhead, flowline and separator crude oil samples for SAPW1 are $9 \pm 0.03^{\circ} \mathrm{C}, 8 \pm 1.04^{\circ} \mathrm{C}$ and $6 \pm 0.11^{\circ} \mathrm{C}$ respectively. This result shows that the wax appearance temperature (WAT) is highest at the wellhead followed by the flowline and separator. In SAPW2, the wellhead, flowline and separator recorded $7 \pm 1.11^{\circ} \mathrm{C}, 6 \pm 1.12^{\circ} \mathrm{C}$ and $4 \pm 0.21^{\circ} \mathrm{C}$ WAT respectively while in SAPW3, $8 \pm 0.15^{\circ} \mathrm{C}, 6 \pm 0.23^{\circ} \mathrm{C}$ and $5 \pm 0.32^{\circ} \mathrm{C}$ WAT were obtained at the wellhead, flowline and separator respectively. The wax appearance temperatures for the three oil wells showed similar trend: Wellhead > Flowline > Separator with SAPW1 (wellhead) recording the highest WAT $\left(9 \pm 0.03^{\circ} \mathrm{C}\right)$. The implication of this result is that the wellhead has the highest tendency for wax precipitation. Determination of a WAT significantly higher than the temperatures expected to be encountered during production indicates the potential for wax deposition problems [4, 17]. 


\section{International Advanced Research Journal in Science, Engineering and Technology}

Vol. 5, Issue 12, December 2018

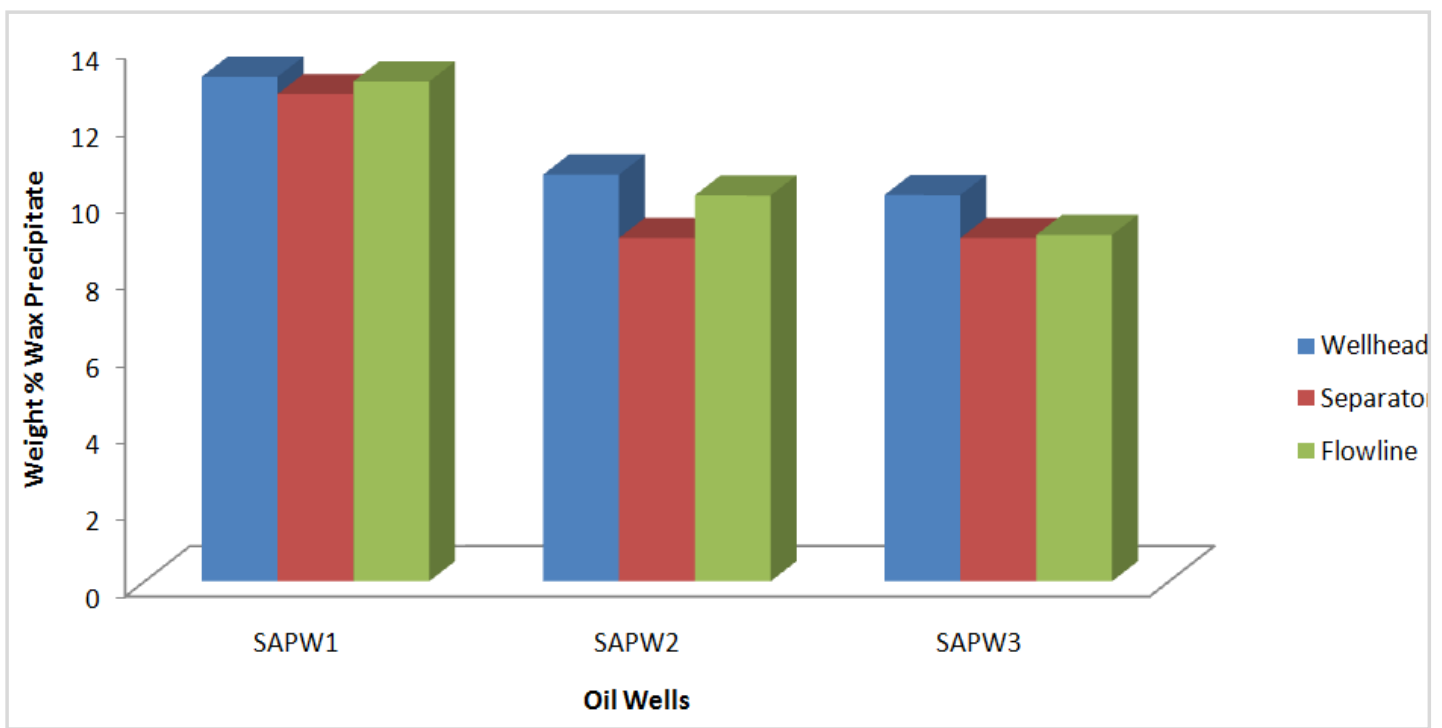

Figure 3: Wax contents of Wellhead, Separator and Flow line crude oil samples from three different wells

Table 2 and Figure 2 show the comparison between the wax appearance temperatures (WAT) and the field operational temperature at wellhead, separator and flowline of the oil wells. It was observed that the wells under study are currently operated at temperatures higher than the WAT. For instance, the field operational temperature at wellhead for SAPW1 is $50^{\circ} \mathrm{C}$ while the WAT is $9 \pm 0.03^{\circ} \mathrm{C}$. The flowline and separator of that same well are operated at $46^{\circ} \mathrm{C}$ and $39^{\circ} \mathrm{C}$ while their wax appearance temperatures are $8 \pm 1.04^{\circ} \mathrm{C}$ and $6 \pm 0.11^{\circ} \mathrm{C}$ respectively. Although this study has established the fact that going through the production line from wellhead to the separator, the wellhead has the highest tendency of wax precipitation followed by the flowline and separator; the temperatures expected to be encountered during production would apparently be higher than the WAT noting that the oil wells are located onshore and less radiation of heat from the fluid to the surrounding formation as it flows up the wellbore would likely be encountered. Secondly, the fluid would not be transferred through low-temperature surface facilities as would have been in the case of offshore facilities. The weight percentage wax content at wellhead, flowline and separator of the oil wells are presented in Table 3 and Figure 3. From the results, SAPW1 precipitated $13.15 \pm 0.12 \%$ wax at wellhead, $13.03 \pm 0.03 \%$ at flowline and $12.70 \pm 0.43 \%$ at the separator. SAPW2 precipitated $10.60 \pm 0.05 \%$ wax at the wellhead, $10.06 \pm 0.03 \%$ at flowline and $8.95 \pm 0.37 \%$ at the separator while $10.07 \pm 0.31 \%, 9.03 \pm 0.15 \%$ and $8.95 \pm 0.12 \%$ wax were generated from wellhead, flowline and separator of SAPW3 respectively. It was observed that the wellhead recorded the highest wax precipitates while the separator recorded the least. The quantities of wax precipitated from the three locations are also in the order: wellhead $>$ flowline $>$ separator. From literature, wax appearance is a function of two variables temperature-pressure represented in Wax Precipitation Envelop [4, 14]. This envelop is often drawn for each crude oil assumed to be representative dead oil [4]. However, this new result has shown that the wax appearance envelope for a specific crude oil may also vary in samples taken along the production line from the wellhead to the separator. This will support the compositional properties used in the models for calculating wax appearance temperature (WAT) for crude oils which include Paraffin, Naphthene and Aromatic (PNA) content of the crude oil $[18,19]$. Different values are given to these individual components and their mole fractions in the equations for wax appearance temperature (WAT) and oil's susceptibility to wax precipitation $[18,19]$.

The fact that the wax appearance temperature (WAT) and wax contents (WC) trends are in the order wellhead > flowline > separator shows a compositional change as the oil comes to the surface and moves along the pipeline with resultant decrease in pressure and temperature. It follows that some components of the oil were deposited along the tubulars in the riser to the wellhead, along the line to the separator and inside the separator.

\section{CONCLUSION}

Different locations along the petroleum production lines are susceptible to various degrees of wax precipitation and possible deposition depending on the temperature and composition changes. The significant deductions from this present research include the following: going through petroleum production line from wellhead to the separator, the wellhead has the highest tendency to precipitate wax, followed by the flowline and the separator, the quantity of wax precipitated or wax content (WC) under any condition is likely to be highest at the wellhead, followed by the flowline and separator. Therefore, the variation in the wax appearance temperature (WAT) and WC along the production line has 


\title{
International Advanced Research Journal in Science, Engineering and Technology
}

\author{
Vol. 5, Issue 12, December 2018
}

offered a hint that the wax precipitation envelope (WPE) for a specific crude oil also varies in samples taken along the production line from the wellhead to the separator.

\section{REFERENCES}

[1]. B. Coto, C. Martos, J. L. Pena, J. J. Espada and M. D. Robustillo. A New Method for the Determination of Wax Precipitation from Nondilluted Crude Oils by Fractional Precipitation, Fuel Science, 87, 2008, 1-14

[2]. C. I. Oseghale, E. J. Akpabio and O. Edebor. Mitigation of Potential Risk of Paraffin Wax Deposition on Oil Pipelines in Niger Delta, Journal of Engineering and Applied Sciences, 7(4), 2012, 348-352.

[3]. R. A. El-Ella and E. Nassef. Determination of Wax Content in Egyptian Crude oils, International Journal of Engineering Trends and Technology, 8(2), 2014, 93-97.

[4]. K. J. Leontaritis. The Asphaltene and Wax Deposition Envelopes. International Journal of Fuel Science and Technology, 14(1-2), 1996, 13-39.

[5]. C. Lira-galeana and A. Firoozabadi. Thermodynamics of wax precipitation in petroleum mixtures, American Institute of Chemical Engineering Journal, 42, 1996, 239-242.

[6]. G. A. Mansoori, T. F. George, G. Zhang and L. Assoufid. Molecular Building Blocks for Nanotechnology: From Diamondoids to Nanoscale Materials and Applications, 2007, 111.

[7]. J. G. Speight. Handbook of Petroleum Product Analysis, New York, John Wiley and Sons, 2015.

[8]. M. Rehan, A. S. Nizami, O. Taylan, B. O. Al-Sasi and A. Demirbas. Determination of Wax Content in Crude Oil, Petroleum Science and Technology, 34(9), 2016, 799-804.

[9]. J. G. Speight. The Chemistry and Technology of Petroleum, New York, Marcel Dekker, Inc, 1991.

[10]. A. M. Elsharkawy, T. A. Al-sahhaf, M. A. Fahim and W. Alzabbai. Determination and Prediction of Wax Deposition from Kuwaiti Crude Oils, Society of Petroleum Engineers (SPE 54006), 1999.

[11]. D. Shields. Predicting Asphaltene and Wax deposition problems in Mexican wells, Offshore, 01, $2000,84$.

[12]. H. Pan and A. Firoozabadi. Thermodynamic Micellization model for Asphaltene Precipitation from Reservoir Crudes at high Pressures and Temperatures, Proceeding of Annual Technical Conference and Exhibition of the Society of Petroleum Engineers, 1997, 91-107.

[13]. G. A. Mansoori. A unified perspective on the phase behaviour of petroleum fluids, International Journal of Oil, Gas and Coal Technology, 2(2), 2009,141-167.

[14]. G. A. Mansoori. Asphaltene, resin, and wax deposition from petroleum fluids: Mechanisms and Modelling. Arabian Journal for Science and Engineering, 21(4997), 1996, 707-723.

[15]. S. Himran, A. Suwono and G. A. Mansoori. Characterization of alkanes and paraffin waxes for application as phase change energy storage medium, Energy Sources, 16(1), 1994, 117-128.

[16]. G. A. Mansoori, H. L. Barnes and G. M. Webster. Petroleum waxes, Journal of Petroleum Science and Engineering. 32(3), $2003,103-114$.

[17]. R. M. Roehner and F. V. Hanson. Determination of Wax Precipitation Temperature and Amount of Precipitated Solid Wax versus Temperature for Crude Oils Using FT-IR Spectroscopy, Energy and Fuels, 15, 2001, 756-763.

[18]. F. Chung, P. Sarathi and R. Jones. Modelling of Asphaltene and Wax Precipitation, National Institute for Petroleum and Energy Research Topical Report, 16 (498), 1991, $65-75$.

[19]. R. Banki, H. Hoteit and A. Firoozabadi. Mathematical Formulation and Numerical Modelling of Wax Deposition in Pipelines from EnthalpyPorosity Approach and Irreversible Thermodynamics, International Journal of Heat and Mass Transfer, 51, 2008,3387 - 3398. 